\title{
Planejamento Urbano no Pampa: instrumentos para revisão do perímetro urbano na fronteira de Jaguarão-BR e Rio Branco-UY
}

\author{
Urban Planning in Pampa: instruments for urban perimeter revision of the border \\ Jaguarão-BR and Rio Branco-UY
}

Planeamiento Urbano en Pampa: instrumentos para la revisión del perímetro urbano de en la frontera Jaguarão-BR y Río Branco-UY

Luana Pavan Detoni Mestranda em Arquitetura e Urbanismo, UFPel, Brasil. luanadetoni@gmail.com

\section{Maurício Couto Polidori \\ Professor Doutor, UFPel, Brasil. mauricio.polidori@gmail.com}

Otávio Martins Peres Professor Mestre, UFPel, Brasil. otmperes@gmail.com 


\section{RESUMO}

O planejamento urbano aborda a cidade como resultante da interação entre inúmeros subsistemas, acumulando teorias e modelos que possibilitam a descrição, análise e simulação do fenômeno urbano. Esse trabalho busca explorar padrões espaciais recorrentes para revisão do perímetro urbano das cidades da fronteira Jaguarão/BR e Rio Branco/UY, a partir do entendimento que ambos os territórios fazem parte do bioma Pampa. A estrutura teórica e metodológica que inclui: a) sistematização das informações da evolução urbana; b) análises espaciais das áreas efetivamente urbanizadas; c) modelagem configuracional urbana, utilizando recursos de grafos e medidas de acessibilidade; d) simulações de crescimento urbano, com recursos de autômatos celulares, considerando os recursos naturais e a dinâmica da urbanização. $O$ trabalho permite avanços na compreensão e no modo de tomada de decisões para o planejamento urbano, com base na diversidade de abordagens, análises e resultados obtidos, objetivando que a cidade do futuro ocorra considerando a preservação natural, a equidade social e a qualidade ambiental.

PALAVRAS-CHAVE: Planejamento Urbano. Bioma Pampa. Perímetro Urbano.

\section{ABSTRACT}

Urban planning approaches the city as a result of the interaction between numerous subsystems, accumulating theories and models that allow the description, analysis and simulation of the urban phenomenon. This work seeks to explore recurrent spatial patterns for the review of the urban perimeter of the Jaguarão / BR and Rio Branco / UY border cities, based on the understanding that both territories are part of the Pampa biome. The theoretical and methodological structure that includes: a) systematization of information on urban evolution; B) spatial analysis of effectively urbanized areas; C) urban configurational modeling, using graph resources and accessibility measures; D) simulations of urban growth, with the resources of cellular automata, considering the natural resources and dynamics of urbanization. The work allows advances in understanding and decision-making for urban planning, based on the diversity of approaches, analyzes and results obtained, aiming at the city of the future considering natural preservation, social equity and environmental quality.

KEY WORDS: Urban Planning. Pampa Biome. Urban Perimeter.

\section{RESUMEN}

ofertas de planificación urbana con la ciudad como resultado de la interacción de numerosos subsistemas, la acumulación de las teorías y modelos que permitan la descripción, el análisis y la simulación del fenómeno urbano. Este trabajo tiene como objetivo explorar recurrentes normas espaciales para la revisión del perímetro urbano de las ciudades de Yaguarón frontera / BR y Blanco / UY río, desde el entendimiento de que ambos territorios son parte del bioma Pampa. El marco teórico y metodológico que incluye: a) sistematización de la información del desarrollo urbano; b) Análisis espacial de las áreas urbanizadas de manera efectiva; c) el modelado configuracional urbana mediante gráficos de recursos y medidas de accesibilidad; d) las simulaciones de crecimiento urbano con recursos autómatas celulares, teniendo en cuenta los recursos naturales y la dinámica de la urbanización. El trabajo permite avances en la comprensión y la forma de la toma de decisiones para la planificación urbana, a partir de la diversidad de enfoques, análisis y resultados obtenidos, con el fin de que la ciudad del futuro se producen teniendo en cuenta la conservación natural, la equidad social y la calidad ambiental.

PALABRAS CLAVE: planificación urbana. Bioma Pampa. Perímetro Urbano. 

modo em que ocorre o processo de crescimento urbano, têm sido diretamente associadas a diferentes modelos formais para alcançar eficiência e sustentabilidade ao fenômeno da urbanização.

Por um lado, há uma grande atratividade das teorias urbanas associadas à ideia de máxima concentração humana e compactação dos grandes centros urbanos, diretamente associados a ganhos na eficiência e intensidade nas relações socioespaciais urbanas. Este modelo está associado diretamente a uma dinâmica de expansão e conversão dos territórios imediatamente adjacentes à cidade preexistente, que tem formado imensos aglomerados e conurbações. Contudo, o modelo de compactação e excessiva concentração da forma urbana, também tem sido associado, como responsável para a supervalorização dos solos urbanos, formação de extensas periferias socialmente segregadas, gentrificação interna e causador de significativos impactos da urbanização sobre áreas de interesse ambiental.

Por outro lado, contemporaneamente, há um crescente debate teórico sobre as dinâmicas de dispersão e fragmentação da forma urbana, como um processo que tem sido essencialmente associado à segregação social do espaço e à conversão indiscriminada da paisagem natural em áreas urbanizadas difusas. Porém, as possibilidades de fragmentação da forma construída têm sido consideradas pela teoria urbana recente, como alternativas à reprodução de territórios urbanos excessivamente compactos, como um caminho teórico para a configuração de uma rede de cidades, ou poli centros, que ocorram adequadamente polarizadas no território.

De modo geral, as teorias dedicadas à localização, à estrutura interna e às dinâmicas ocorridas nas cidades trata-se de abstrações teóricas, desenvolvidas nas áreas de conhecimento da economia, da geografia, da ecologia, da sociologia e da morfologia urbana, dentre outras. Em essência, estas distintas abordagens convergem ao pressuposto que existe uma ordem intrínseca ao fenômeno da urbanização, relativos aos diferentes sistemas que operam na rede urbana - sociedade, ecologia e espaço construído, os quais mantêm relações de proporcionalidade nas grandezas de tamanho, quantidade e forma das cidades (BATTY, 2013). Nestes termos, a morfologia urbana estuda a forma, a estrutura e os processos de transformação urbana, mediante abordagens dos objetos construídos, das feições do espaço urbano e das características da paisagem natural, com o desejo de compreender as múltiplas relações e os fenômenos que deram origem a paisagem urbana (LAMAS, 2011).

Para os estudos urbanos de base morfológica, modelos urbanos são construções teóricas abstratas capazes de descrever os objetos que existem, existiram ou podem vir a existir nas cidades. Sob outra perspectiva, modelos urbanos podem ser compreendidos como instrumentos para a análise e investigação sobre a complexidade do fenômeno urbano. Atualmente a modelagem urbana vem sendo apoiada por processamentos computacionais, construídas como ferramentas digitais de investigação sobre o presente, o passado e o futuro das cidades, servindo a cientistas e planejadores para capturar o fenômeno e explorar cenários, atuando como uma ponte entre a teoria e a prática (BATTY, 2013). 


Figura 1: Mapa da Evolução Urbana de Jaguarão/BR e Rio Branco/UY

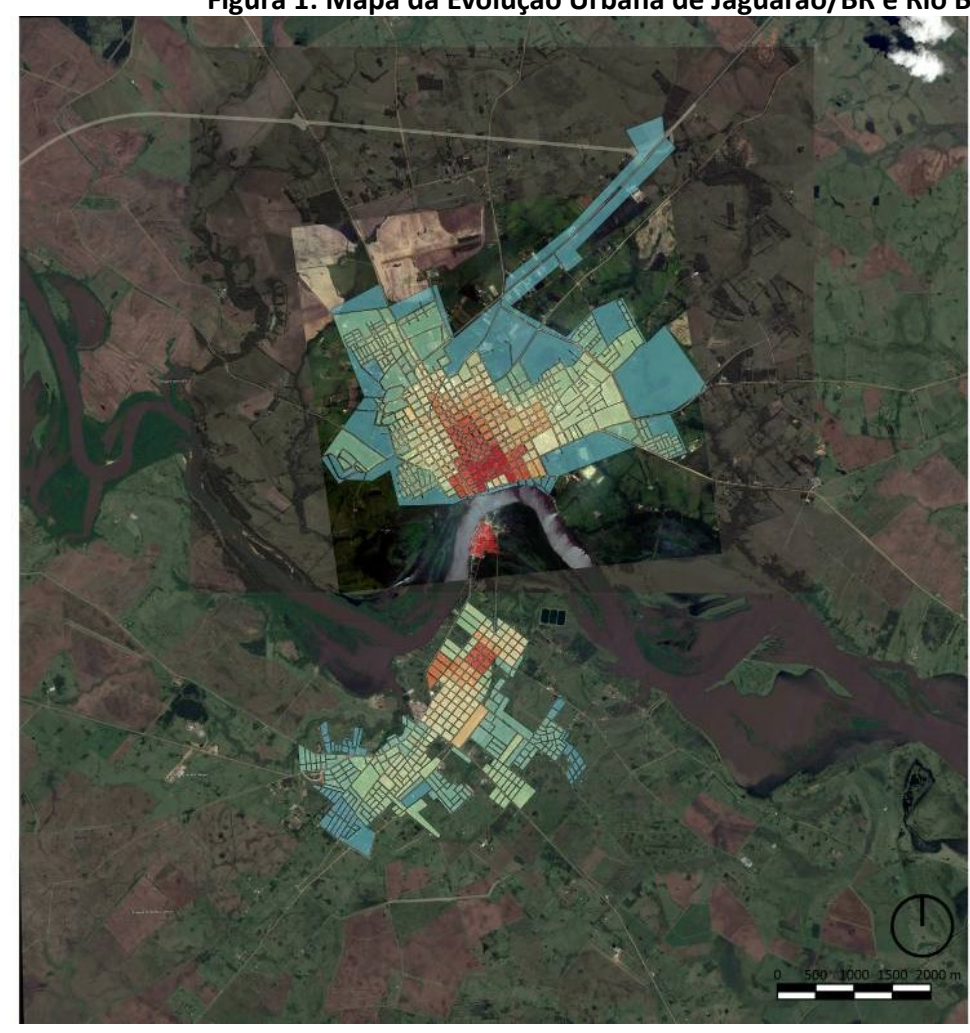

Estudos para Expansão do Perímetro Urbano Jaguarão/BR e Rio Branco/UY

Fonte: Autores, 2016.

Deste conjunto diverso de informações, sistematizadas em ambiente SIG, foi construído um mapa vetorial único, apresentado na Figura 1 acima, que reconstrói o processo de evolução urbana das cidades de Jaguarão/BR e Rio Branco/UY ao longo do tempo, servindo de informação fundamental para abordagem do processo de crescimento urbano e construção de alternativas futuras para o estudo da morfologia e do perímetro urbano.

A partir dos dados da historiografia urbana, um primeiro conjunto de análises espaciais avançadas realizadas aplicam recursos de geoprocessamento de análises de abrangência de buffers a partir das áreas efetivamente urbanizadas, do estágio atual e de um estágio passado da forma urbana. A partir da aplicação da medida de buffers sobre as áreas efetivamente urbanizadas, pretende-se uma apreensão morfológica do modo de relacionamento da forma urbana com a paisagem natural de entorno, aplicando este recurso de análise direta e estática. As figuras $2 \mathrm{a}$ e $2 \mathrm{~b}$ a seguir, apresentam as análises de abrangência das áreas efetivamente urbanizadas para o ano de 2013 e 1964, respectivamente. As análises foram construídas com quatro primeiras medidas de buffers de 250 metros, a fim de considerar áreas de influências imediatas (em variações de amarelos), seguidas pela sucessão de três buffers com medidas de 500 metros (em variações de laranjas), seguidos por dois buffers de 1.000 metros e, 
apresenta o mapa dos eixos viários, desconsiderando os eixos com valores de acessibilidade inferiores a $60 \%$, considerando apenas os espaços urbanos com maior privilégio locacional e indicam os eixos com melhores condições de acesso relativo. A partir do mapa de acessibilidades superiores, foi realizada a análise de sucessivos buffers, semelhante ao realizado sobre as áreas efetivamente urbanizadas, desta vez considerando uma morfologia urbana com maiores privilégios locacionais. Desta forma, a análise de abrangência para redefinição do perímetro ocorre considerando não a totalidade da forma urbana, mas apenas seu extrato superior de eficiência de acesso.

Para os estudos de simulação de crescimento urbano, foram criados três cenários diferentes, processados através do software CityCell - Urban Growth Simulator (POLIDORI, 2015) que aplica recursos de modelagem de crescimento urbano em espaços celulares com autômatos celulares.

O CityCell opera sobre uma base espacial no formato de um grid bidimensional regular com células quadradas, cujo tamanho das células foi definido de $200 \mathrm{~m} \times 200 \mathrm{~m}$. O tamanho da célula está implantado pelos seguintes motivos principais: a) a ideia é abranger numa célula de atributos urbanos e naturais, simultaneamente; sendo assim, para o caso as células devem ser maiores que o quarteirão tradicional, cuja quadrícula varia de 70 a $120 \mathrm{~m}$; b) para processamento dos dados, quanto maior a célula melhor é o desempenho do modelo, deste modo, o tamanho adequado das células se encontra na maior célula possível que permita descrever a cidade em estudo e o ambiente de entorno, com bordas e superfícies que permitam a visualização da informação.

A partir da grid o ambiente urbano e natural foi descrito. O modelo aplica um algoritmo de diferença espacial, identificação de potencias e alocação de crescimento, simula interações espaciais que geram tensões para um par de células e compõem uma medida de centralidade celular. Essa medida de centralidade celular representa uma diferenciação abstrata do ambiente urbano relacionada com os locais de maior atratividade urbana, o modelo calcula potenciais de crescimento identificando locais com maior oportunidade a partir da proximidade dos locais com maior centralidade.

A área das simulações considera uma área de trabalho que abrange ambas as cidades e o ambiente de entorno, de modo a considerar a influência mútua do crescimento entre as duas cidades e entre as paisagens urbana e natural. A partir da delimitação da área de estudo, o modelo permite a livre inclusão de variáveis ou atributos, que podem ser dos tipos urbano, natural ou institucional, os quais podem assumir o papel de atração ou resistência à urbanização. Geralmente, as variáveis dos atributos naturais representam os fatores do ambiente natural, modificados ou não pela ação humana, como os sistemas de águas superficiais, cobertura do solo e fatores geomorfológicos. Os atributos urbanos representam o mapeamento do solo já urbanizado e podem receber diferenciação através de pesos e intensidades de urbanização. Já os atributos do tipo institucional possibilitam representar mecanismos legais ou práticas de planejamento urbano, como é o caso de legislações de 


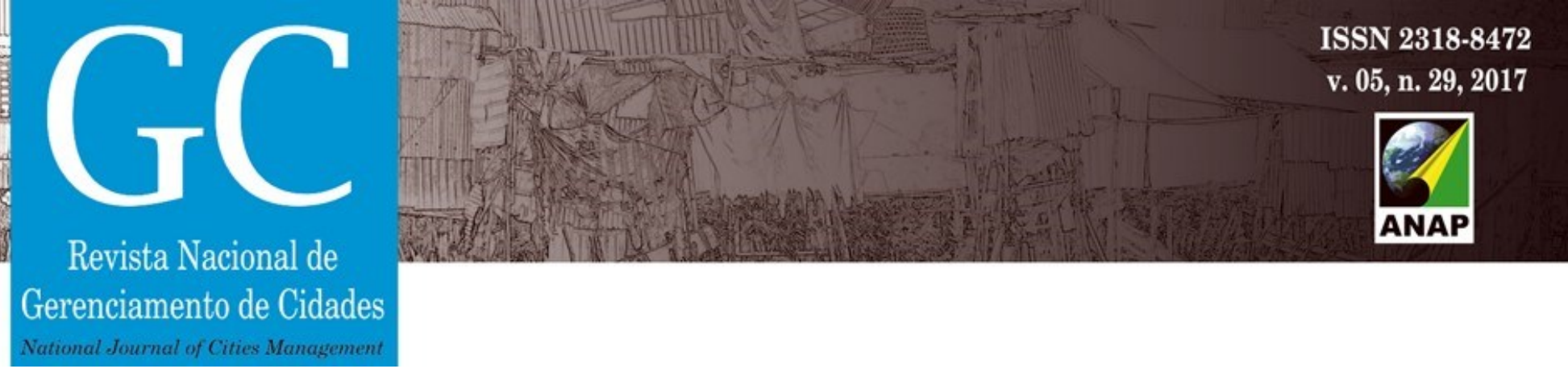

restrição ou incentivo à urbanização. Ainda, os atributos urbanos, naturais ou institucionais, que operam de modo a promover ou restringir o crescimento urbano, podem assumir características que o permitem ser alterados no processo de crescimento, ou são fixos à mudança durante o processo (SARAIVA, 2015).

Os inputs do modelo foram construídos de modo a representar 12 atributos, apresentados na figura 4 e a seguir descritos: Rio Jaguarão, natural, resistência e freezing, construído a partir do mosaico ambiental (a); Área de Alagamento de cota 6,2 metros, natural e resistência, construído a partir dos dados de altitudes (b); Banhados, natural, resistência e freezing, construído a partir do mosaico ambiental (c); Vegetação Nativa, natural, resistência e mutable, construído a partir do mosaico ambiental (d); Atributo Natural Randômico, resistência e mutable, com pesos entre 1 e 5, natural e resistência, usado para incluir um grau de aleatoriedade na simulação (e); Geomorfologia, natural, resistência e mutable, construídos a partir da bacias hidrográficas (f); Linhas de drenagem de 100ha, natural, resistência e freezing, construídas a partir das bacias com áreas de 100ha (g); Linhas de drenagem de 10h, natural, resistência e mutable, construídas a partir das bacias com áreas de 10ha (h); Área Urbanizada, urbano, atração e mutable, construído sobre a imagem base (i); Vias de acesso, urbano, atração e mutable (j); Preservar, natural, resistência e freezing, construído com base nas áreas do Zoneamento Ambiental Urbano (I); Urbanizar, institucional, atração e mutable, construído com base no Zoneamento Ambiental Urbano ( $\mathrm{m})$.

A simulação de crescimento foi processada para três cenários diferentes: Cenário A: que utilizou apenas os atributos naturais e urbanos; Cenário B: incluiu o input (figura 4l) das áreas de preservação do Zoneamento Ambiental Urbano; Cenário C: utilizou os atributos do Cenário $B$ e incluiu o input (figura $4 \mathrm{~m}$ ) da indução da urbanização nas áreas aptas definidas pelo Zoneamento Ambiental Urbano. A regra utilizada nas simulações foi a Threshold Potential (POLIDORI, 2004), que assume a medida de centralidade como indicador de qualidade locacional, sendo o potencial de desenvolvimento de cada célula derivado da diferença entre a centralidade da célula e a centralidade máxima em sua vizinhança. As simulações foram geradas para 40 anos, adotando-se a taxa de crescimento de $2 \%$ ao ano. 


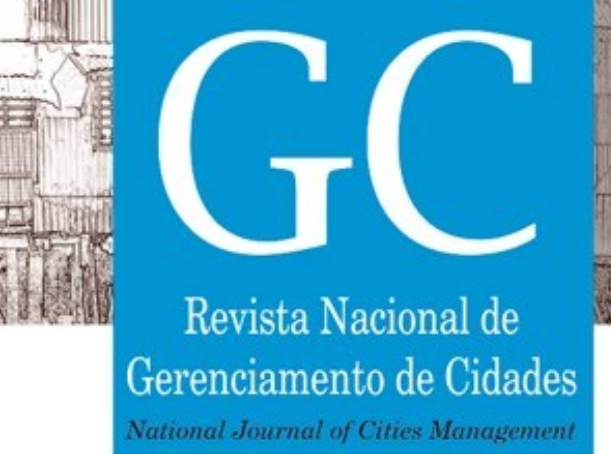

ISSN 2318-8472

v. 05, n. 29,2017

Figura 4: Rio Jaguarão (a); Área de alagamento 6,2 metros (b); Banhados 2009 (c); Vegetação nativa (d); e) Random 1-5 (e); Topografia (f); Linhas de drenagem de 100h (g); Linhas de drenagem de 10h (h); AEU (i); VIAS (j); Preservar (I); Urbanizar (m)



Fonte: Autores, 2016.

Figura 5: Cell Type na $40^{\circ}$ iteração - Cenários A, B e C



Fonte: Autores, 2016.

A figura 5 apresenta o resultado do CellType, ou fenótipo urbano, para o ano de 2055, para os cenários A, B e C, respectivamente. Nota-se que os processos simulados diferem-se, principalmente no que se refere à compactação e fragmentação da forma urbana resultante. 




gura 7: Sobreposição de resultados das diferentes análises e de modelagem urbana para Jaguarão e Rio Branco, considerando área efetivamente urbanizada (amarelo), acessibilidades (azuis) e simulações de crescimento

Fonte: Autores, 2016.

\section{CONSIDERAÇÕES FINAIS}

A proposta de expansão do perímetro urbano, realizada mediante um conjunto de análises em base de dados SIG, juntamente com a aplicação de recursos de modelagem e simulação urbana, permite uma abordagem instrumental para o planejamento urbano, de modo que a cidade do futuro pondere a preservação natural, a equidade social e a qualidade ambiental. A revisão do perímetro urbano trata-se de uma ação específica do processo de planejamento urbano, que deve ser compreendida e considerada com as demais etapas desse processo, como o zoneamento ambiental, o zoneamento de densidades, os regimes construtivos e de uso do solo, e também com os temas de mobilidade, habitação, entre outros.

Os estudos de morfologia, modelagem configuracional e simulação de crescimento urbano, podem ser recursos e instrumentos auxiliares nas ações complexas e dinâmicas, cada vez mais necessárias ao planejamento urbano contemporâneo. O presente trabalho destaca-se por apresentar um método definido e avançado, a fim de que o crescimento e a expansão urbana ocorram, considerando variáveis do ambiente natural, da eficiência urbana e das preexistências construídas e urbanizadas. Avalia-se que os resultados e processos desse 
trabalho possam ser replicados em outras cidades, além de apoiar designadamente o planejamento e a revisão do perímetro urbano das cidades em questão, Jaguarão e Rio Branco, contribuindo dessa forma efetivamente para a aproximação dos instrumentos de estudos e das práticas de planejamento urbano.

\section{REFERÊNCIAS}

ALMEIDA, Claudia; CÂMARA, Gilberto. Geoinformação em Urbanismo: Cidade Real X Cidade Virtual. Oficina de Textos. 2007.

BATTY, Michael. The New Science of Cities. MIT Press. 2013.

ESRC. Urban Transformations: Scoping Report on Research Priorities. Economic \& Social Research Council, London. 2013.

HILLIER, Bill et al. Natural movement. Environment \& Planning B 20. 1993.

KRAFTA, Romulo. Modelling Intraurban configurational development. Environment and Planning B: Planning and Design, v. 21. London: Pion, 1994.

LAMAS, José M. Ressano Garcia. Morfologia urbana e desenho da cidade. Versão original 1989. 6. ed. Lisboa. Fundação Calouste Gulbenkian: Serviço de Educação e Bolsas, 2011.

MARTINS, Roberto Duarte. A ocupação do espaço na fronteira BrasilUruguay: a construção da cidade de Jaguarão. Tese. (Doutorado em Histórias Especializadas). Escola Técnica Superior de Arquitetura. Universidade Politécnica da Catalunha, 2001.

PAIM, Daniel. Comportamento agregado da medida de acessibilidade Na descrição da morfologia urbana. Dissertação de Mestrado UFPel PROGRAU. Pelotas. 2015.

PERES, Otávio Martins. Crescimento Urbano e Hidrografia: dinâmicas morfológicas e articulação à paisagem natural. Dissertação de Mestrado UFPel PROGRAU. Pelotas, 2010.

POLIDORI, Maurício. C. Crescimento urbano e ambiente: um estudo exploratório sobre as transformações e o futuro da cidade. Tese de Doutorado UFRGS PPGECO. [S.I.], 2004.

POLIDORI, Maurício. C. Urban Metrics 2.1.1. Disponível em: http://wp.ufpel.edu.br/urbanmetrics/. Acesso: junho, 2015.

POLIDORI, Maurício. C. Crescimento urbano e ambiente: um estudo exploratório sobre as transformações e o futuro da cidade. Tese de Doutorado UFRGS PPGECO. [S.I.], 2004.

PORTUGALI, Juval. Self-organization and the city. Berlin: pringer, 2000.

PUCCI, Adriano Silva. O Estatuto da Fronteira Brasil - Uruguai. Brasília: Fundação Alexandre Gusmão, 2010.

SARAIVA, Marcos.; POLIDORI, Maurício. C.. CityCell 4.2 Curupira Software. Disponível em: https://wp.ufpel.edu.br/citycell/ Acesso: junho, 2015.

SARAIVA, M. Simulação de crescimento urbano em espaços celulares com a medida de acessibilidade: método e estudo de caso em cidades do sul do Rio Grande do Sul. Dissertação de Mestrado PROGRAU/UFPel. Pelotas. 2013. 
